\title{
Trivium
}

Revue franco-allemande de sciences humaines et sociales - Deutsch-französische Zeitschrift für Geistesund Sozialwissenschaften

$31 \mid 2020$

La culture politique de la République romaine

\section{Gentilizische Konkurrenz und kaiserliches Urteil. Die politischen Praktiken der augusteischen Aristokratie}

\section{Frédéric Hurlet}

Traducteur: Andreas Wittenburg

\section{OpenEdition}

Journals

Édition électronique

URL : https://journals.openedition.org/trivium/7088

DOI : $10.4000 /$ trivium.7088

ISBN : 1963-1820

ISSN : 1963-1820

\section{Éditeur}

Les éditions de la Maison des sciences de l'Homme

\section{Référence électronique}

Frédéric Hurlet, „Gentilizische Konkurrenz und kaiserliches Urteil. Die politischen Praktiken der augusteischen Aristokratie“, Trivium [Online], 31 | 2020, online erschienen am 30 Juni 2020, abgerufen am 24 August 2021. URL: http://journals.openedition.org/trivium/7088 ; DOI: https://doi.org/10.4000/ trivium.7088

Ce document a été généré automatiquement le 24 août 2021.

\section{c) () $९$}

Les contenus des la revue Trivium sont mis à disposition selon les termes de la Licence Creative Commons Attribution - Pas d'Utilisation Commerciale - Pas de Modification 4.0 International. 


\section{Gentilizische Konkurrenz und kaiserliches Urteil. Die politischen Praktiken der augusteischen Aristokratie}

\section{Frédéric Hurlet}

Traduction : Andreas Wittenburg

\section{NOTE DE L'ÉDITEUR}

\section{Originalausgabe | édition originale}

"Concurrence gentilice et arbitrage impérial. Les pratiques politiques de l'aristocratie augustéenne«, Politica Antica, 2, 2012, S. 33-54.

Wir danken Herrn Frédéric Hurlet und der Zeitschrift Politica Antica für die freundliche Genehmigung, diesen Artikel in deutscher Übersetzung zu publizieren.

Nous remercions M. Frédéric Hurlet et la revue Politica Antica de nous avoir accordé l'autorisation de traduire ce texte pour le présent numéro.

1 Die Feststellung, dass die Konkurrenz zwischen Aristokraten im Zentrum des politischen Handelns in der Römischen Republik stand, ist nicht sonderlich originell, denn wir haben uns daran gewöhnt, uns das politische Leben Roms als eine Folge von Auseinandersetzungen um die Erlangung von honores zwischen Einzelnen, Familien oder gar Parteiungen vorzustellen. Dagegen wird weniger oft unterstrichen, dass dieses Phänomen keineswegs ein Faktor der Destabilisierung und der Korrumpierung von Gesellschaften ist, sondern ganz im Gegenteil ihren Zusammenhalt stärken konnte. Genau daran hat Karl-Joachim Hölkeskamp kürzlich erinnert und sich dabei auf die Arbeiten des deutschen Soziologen Georg Simmel gestützt, um die sozialisierenden Wirkungen der Konkurrenz hervorzuheben. ${ }^{1}$ Ein weiteres Ergebnis der Untersuchungen Hölkeskamps zur Römischen Republik ist es, dass er dem römischen 
Volk die Rolle des Schiedsrichters der Rivalitäten innerhalb der Aristokratie zuspricht. Dadurch werden die Volksversammlungen - die contiones und die Comitien - zu bedeutenden Akteuren bei der Konsensbildung, und es wird ihnen so eine größere funktionelle Bedeutung zuerkannt, ohne dass man gezwungen ist, von einer Demokratie in Rom zu sprechen. ${ }^{2}$ Es ist aber auch deutlich, dass die Krise der Römischen Republik die Konkurrenz zwischen den sogenannten imperatores in einem derartigen Ausmaß belebt, dass sie tödlich wird. Die politische Auseinandersetzung zwischen Caesar und Pompeius, der sich daraus ergebende Bürgerkrieg und die Ermordung Iulius Caesars sind schlagende Beweise für die Entfesselung der Gewalt vom Ende der 50er bis in die 40er Jahre v. Chr.

Die zahlreichen Siege, die Iulius Caesar erlangte, machten ihn zum Herrn des politischen Spiels und gipfelten in einer absoluten Form der Kontrolle: der Diktatur auf Lebenszeit. Sie wurde ihm zu Beginn des Jahres $44 \mathrm{v}$. Chr. übertragen, war aber infolge seiner Ermordung an den Iden des März desselben Jahres nur von kurzer Dauer. Dieses tragische und von Natur her unerwartete Ereignis ließ eine bisher unbekannte Situation entstehen, die in einer neueren Doktorarbeit von Raphaëlle Laignoux glänzend untersucht worden ist. ${ }^{3}$ Aus dieser Untersuchung geht hervor, dass der Tod Caesars Energien innerhalb der Aristokratie freisetzt, indem er eine Leere und eine Angst vor der Leere schafft. Das bringt eine ganze Reihe von Konsuln und Konsularen oder Praetoren und Praetoriern, die plötzlich in den Vordergrund rücken, dazu, im Rahmen dieses neuerlichen Kampfs um die Macht zahlreiche Reden und Aufrufe zu verbreiten. Man wird Zeuge eines Kriegs der Bilder und Diskurse, erkennbar an einer Masse politischer Äußerungen, die über Medien unterschiedlicher Art verbreitet wurden. Da sind die Reden, sei es im Senat oder vor dem in der Volksversammlung oder in einer contio zusammen gekommenen Volk und vor den Soldaten. Da sind die Münzen, Gemmen, Skulpturen und Monumente. Man sieht dabei, wie sich die Konkurrenz zwischen den herausragenden Mitgliedern der römischen Aristokratie stark belebt. Die wichtigsten dieser Männer waren im Jahr 44-43 v. Chr. M. Brutus (Praetor des Jahres 44), Q. Cassius Longinus (Praetor des Jahres 44), Marcus Antonius (Konsul des Jahres 44), Lepidus (magister equitum im Jahre 44), Decimus Brutus (Prokonsul der Gallia Cisalpina im Jahre 44-43), Octavian und Sextus Pompeius. Man könnte weitere Persönlichkeiten hinzufügen wie den Konsul des Jahres 44 Dolabella, die Konsuln des Jahres 43 A. Hirtius und C. Vibius Pansa Caetronianus oder noch den Konsul des Jahres 42 L. Antonius, wobei Letztere durch die Bekleidung des Konsulats für einen Moment eine vorrangige Rolle spielten, bevor das Schicksal sie verschwinden oder in den Hintergrund treten ließ. Aus diesem Kampf zwischen den herausragenden Mitgliedern der Aristokratie sollten ein einzelner Mann, Octavian, und seine Familie als Sieger hervorgehen, und das am Ende eines harten Wettbewerbs, der durch die sukzessive Eliminierung seiner Gegner beendet wurde. Eine Folge der politischen Praktiken, wie sie zwischen dem Tod Caesars im Jahre 44 v. Chr. und der Rückkehr Octavians 29 v. Chr. belegt sind, war die verstärkte Personalisierung der Macht. Dazu kam eine neue Art der politischen Kommunikation, die nach Actium von dem späteren Augustus eingesetzt und von nun an von dem Sieger des Bürgerkriegs monopolisiert wurde (z. B. durch den systematischen Rückgriff auf Münztypen oder ikonographische Motive).

Der militärische Sieg des Octavian hatte sich zwar nachteilig auf die globale Kontrolle durch die sich ständig erneuernde senatorische Aristokratie ausgewirkt, aber er 
bedeutete eine Stabilisierung des politischen Lebens und eine Rückkehr zu den Praktiken der Zeit vor dem Triumvirat. Bereits Tacitus hat unterstrichen, dass die Errichtung dieser neuen Ordnung keineswegs von den Senatoren bekämpft wurde, sich mit deren stillschweigendem Einverständnis und im Geiste der Zusammenarbeit vollzog. ${ }^{4}$ Diese Sichtweise ist von manchen Historikern des 20. Jahrhunderts übernommen worden, darunter besonders von Ronald Syme, der gezeigt hat, dass die Wiederherstellung des Friedens unter den Bürgern für viele in der Anerkennung des neuen Regimes durch eine Aristokratie bestand, die Sicherheit erhoffte und ihr althergebrachtes soziales Ansehen zurückgewinnen wollte. ${ }^{5}$ Das ist die Erklärung dafür, dass die Schaffung des Prinzipats durch Augustus auf eine aristokratische Restauration hinauslief. Letztere hat unvermeidlich dazu beigetragen, den politische Kampf neu zu beleben, ${ }^{6}$ wobei es nicht mehr um die wesentlichen Machtpositionen ging, die inzwischen vom Kaiser monopolisiert wurden. Das Ziel dieser Untersuchung ist es zu bestimmen, in welchem Maße und auf welche Weise sich die traditionelle und harte Konkurrenz der Aristokraten an die Existenz einer neuen, an der Spitze der res publica stehenden, überragenden Autorität in der Person des princeps anpasste.

\section{Die Konkurrenz zwischen den Aristokraten auf der Suche nach neuen Regeln: der princeps als Schiedsrichter}

4 Eine der Folgen der Begründung des Prinzipats war, dass Augustus jetzt der Schiedsrichter in dem Wettbewerb wurde, in dem sich die Senatoren bei der Wahl zu den Magistraturen, dem Zugang zu den Priesterämtern, der Übernahme der Regierungsgewalt in den Provinzen oder auch bei der Beförderung ihrer Familien in den Rang von Patriziern weiterhin als Rivalen gegenüberstanden. Das bedeutet nicht, dass das römische Volk in der Form der contiones und der Comitien seine eigene Funktion als Schiedsrichter verlor, die ihm unter der Republik zukam, jedenfalls nicht sofort, aber es war nicht mehr die einzige handelnde Kraft, die zwischen den Mitglieder der Aristokratie bei ihren Kämpfen um die Ehrenstellungen eine Entscheidung fällte, und außerdem nicht mehr die wichtigste. Es ist inzwischen allgemein anerkannt, dass die Comitien sich unter Augustus weiter häufig versammelten und auch sowohl an den Wahlen der Beamten wie an der Verabschiedung von Gesetzen beteiligt waren. Virginie Hollard hat in Hinblick auf die Abstimmung in den Komitien den Begriff des »Rituals" verwendet und gezeigt, wie sie am Ende unter die Kontrolle der kaiserlichen Gewalt fiel. ${ }^{7}$ Mit der Entstehung des Prinzipats vollzog sich eine Neuordnung der politischen Gleichgewichte insoweit, als die Konkurrenz zwischen den Aristokraten sich änderte.

Die wesentliche Ehrenstellung, die die Aristokraten anstrebten, blieb unter Augustus das Konsulat, das weiterhin die auf Wahl beruhende ordentliche Magistratur an der Spitze des cursus honorum war und seinem Inhaber sowohl aufgrund der ausgeübten Funktionen wie kraft des sich daraus ergebenden konsularischen Rangs sehr großes Ansehen verlieh. ${ }^{8}$ Die dauernde Ausübung des höchsten Amtes durch Augustus zwischen 31 und $23 \mathrm{v}$. Chr. erregte natürlich die Unzufriedenheit der römischen Aristokratie, die über einen so langen Zeitraum dauerhaft des einen der beiden Konsulate beraubt war. Die Aufgabe des Konsulats durch Augustus im Jahre 23 und die darauffolgende Übernahme der tribunizischen Gewalt erklären sich im Übrigen in erster Linie aus dem Willen, den Zugang zum Konsulat und zum konsularischen Rang 
für eine größere Zahl ehemaliger Praetoren zu öffnen. ${ }^{9}$ Derartige Entscheidungen beeinflussten das Phänomen der Konkurrenz unter Aristokraten, da sie einen zweiten Platz als Konsul freiließen, der die Begehrlichkeiten anfachte. Da es mehr Kandidaten gab, als Beamte zu wählen waren, trug das - nach der Parenthese des Triumvirats - zur Wiederbelebung der Wahlkämpfe bei, die manchmal durchaus unruhig waren.

Eine aufschlussreiche Episode für die fortdauernden Spannungen, die sich aus dem natürlichen Streben der Aristokratie nach der Bekleidung des Konsulats ergaben, sind die Wahlen der Konsuln des Jahres $21 \mathrm{v}$. Chr. und die ihnen vorangehende Wahlkampagne. Ich habe den Fall schon in zwei anderen Publikationen behandelt, aber nur kurz. ${ }^{10}$ Es ist daher nützlich, hier darauf zurückzukommen, um die Untersuchung der Passage bei Cassius Dio zu vertiefen, die unsere einzige Quelle zu den in Frage stehenden Ereignissen darstellt. Aus diesem Text geht hervor, dass die Entscheidung des Augustus, nach dem Verzicht des Jahres 23 nicht mehr Kandidat für das Konsulat zu sein, einen Zustand der Aufgeregtheit schuf, der zu einer Konfrontation bei der Wahl zwischen zwei Aristokraten führte, dem Q. Aemilius Lepidus und einem L. Silvanus, der vielleicht ein L. (Iunius) Silanus war. ${ }^{11} \mathrm{Nach}$ der Intervention des Augustus wurde Q. Aemilius Lepidus schließlich im Laufe des Jahres 21 gewählt, und zwar spät und unter der Leitung des einzigen Konsuls, der im Jahre 22 für 21 gewählt worden war, nämlich M. Lollius. ${ }^{12}$ Diese Umstände sind wohlbekannt, aber man kann die Analyse noch vertiefen, wenn man aus dem Text des Cassius Dio noch die folgenden zusätzlichen Lehren zieht: Die lange Dauer der Wahlunruhen sind ein Ergebnis des Missmuts des Volkes, die Entscheidung des Augustus zu akzeptieren, dass er nicht mehr Konsul sein will; die Heftigkeit eines Wahlkampfs, den Cassius Dio durch

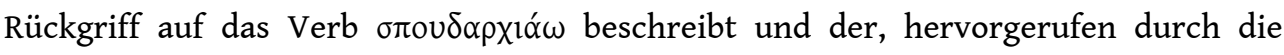
Rivalität zwischen zwei Aristokraten, in echten Aufruhr ausartete; der auf Bitten von Senatoren aus der Ferne, aus Sizilien, ergangene Schiedsspruch des Augustus, der die beiden Kandidaten zu sich rief und ihnen befahl, zum Zeitpunkt der Versammlung der Comitien nicht in Rom zu sein; der mangelnde Respekt der beiden Kandidaten gegenüber den von Augustus ergangenen Ruheappellen, was erklärt, warum Q. Aemilius Lepidus »spät« (ỏ $\psi \varepsilon ́$ ) im Jahre 21 gewählt wurde. Das alles bedeutet, dass die Konkurrenz zwischen Aristokraten, die sich in den ersten Jahren des neuen Regimes zeigt, wie in der republikanischen Zeit eine Quelle für Unruhen ist und zugleich eine heikle Angelegenheit für den princeps als Schiedsrichter.

7 Wahlunruhen sind von neuem in einem ähnlichen Zusammenhang für das Jahr 19 v. Chr. belegt, auch wenn es Augustus selbst war, der in dem betreffenden Jahr intervenierte, um einen Kandidaten zu verhindern, den er keinesfalls zum Konsul gewählt sehen wollte, in diesem Falle L. Egnatius Rufus. Er veranlasste an seiner Stelle die Wahl eines anderen, Q. Lucretius Vespillo. Das Manöver gelang dank der Mitarbeit des einzigen zum Beginn des Jahres $19 \mathrm{im}$ Amt befindlichen Konsuls, C. Sentius Saturninus. Dieser hatte L. Egnatius Rufus verboten zu kandidieren, und er weigerte sich, wie es sein Recht war, ihn zum Konsul zu erklären, als Rufus seine völlig illegale Kandidatur aufrechterhalten hatte und von den Komitien gewählt worden war. ${ }^{13}$ Die vergleichende und genauere Analyse der Zeugnisse des Cassius Dio und des Velleius Paterculus erbringt für das Phänomen der Konkurrenz verschiedene sich ergänzende Informationen, die Unterschiede zu den Ereignissen von 22-21 belegen. Der Ernst der Lage hängt noch immer mit der von Augustus erklärten Weigerung zusammen, das Konsulat zu übernehmen, und sie artet in Rom erneut zum Aufruhr aus, der diesmal 
Taten wie »Morde« ( $\sigma \varphi \alpha \gamma \alpha i$ ) einschließt. Zunächst ist da die Gegnerschaft zwischen dem Volk, das bei der Wahl der Komitien für Egnatius Rufus Partei ergreift, und der gesamten oder einem Teil der Aristokratie, die den im Amt befindlichen Konsul unterstützt und an Augustus appelliert, den Unruhen ein Ende zu bereiten. Darauf erfolgt ein neuerlich aus der Ferne auf Ersuchen der Senatoren verkündeter Schiedsspruch des Augustus, aber in ganz anderer Weise als bei den $21 \mathrm{v}$. Chr. getroffenen Entscheidungen. Augustus wählt nämlich einen unter den vom Senat zu ihm geschickten Gesandten als Konsul aus, und zwar Q. Lucretius Vespillo. Der Weg, auf dem dieser ins Konsulat gelangt (nicht vor August 19) ${ }^{14}$, bleibt indes unter institutionellen Gesichtspunkten unklar. Cassius Dio gibt an, Augustus habe ihn

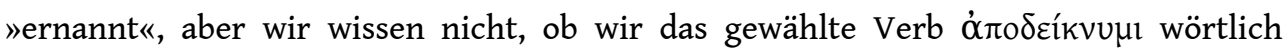
nehmen sollen oder ob man sich unter diesem Verb eine weniger direkte Intervention des Princeps in Form einer Empfehlung (commendatio) vorstellen soll, die den Komitien keine andere Wahl ließ als sich anzuschließen. ${ }^{15}$ Diese Episode ist aus mehreren Gründen ganz besonders aufschlussreich in Hinblick auf die von Augustus überlieferten Schiedssprüche. Sie zeugt zuallererst von dem mangelnden Einverständnis, das vom Volk und dem Prinzeps gegenüber den von der Aristokratie getroffenen Entscheidungen über die Wahl eines der beiden Konsuln zum Ausdruck gebracht werden konnte. Außerdem zeigt sie, dass in diesem Bereich das letzte Wort Augustus zufiel. Es ist statthaft, im Volk in der augusteischen Zeit weiterhin einen Schiedsrichter bei Rivalitäten zwischen Aristokraten zu sehen, aber unter der Bedingung, dass man unterstreicht, dass eine solche Rolle ihrerseits dem Schiedsspruch des Augustus unterworfen war und sich unter dem Einfluss der verschiedenen Reformen allmählich abschwächte. Darunter ist die Schaffung der Destinationscenturien im Jahre $5 \mathrm{n}$. Chr. zu nennen und die Übertragung der Wahlen auf den Senat im Jahr $14 \mathrm{n}$. Chr.

Die Verwicklung des Augustus in die Wahlen zum Konsulat beschränkt sich nicht auf seine verschiedenen Interventionen zum Zeitpunkt der Wahlkampagnen, um die Ordnung wiederherzustellen oder um den einen früheren Praetor eher zu begünstigen als einen anderen. Seine auctoritas war in einem Maße ausschlaggebend, dass seine Stellungnahme für einen beliebigen Kandidaten für eine beliebige Magistratur entscheidend war. Das ist eine offenkundige Tatsache, an die von den Quellen häufig erinnert wird. Eine Passage in den Annalen des Tacitus erwähnt, dass Augustus den Aufstieg des C. Ateius Capito, eines bekannten Juristen, zum Konsulat beschleunigt habe. Er wurde im Jahre $5 \mathrm{n}$. Chr. zum consul suffectus gewählt, um ihm so Vorrang vor einem anderen anerkannten Juristen, Antistius Labeo, zu geben. Letzterer stand dem neuen Regime kritischer gegenüber, und er kam aus diesem Grunde nicht über den Rang eines Praetors hinaus. ${ }^{16}$ Ebenfalls bei Tacitus erfährt man, dass D. Iunius Silanus, der Bruder des consul suffectus des Jahres $15 \mathrm{n}$. Chr. und frühere Liebhaber der Enkelin des Augustus, zu keiner Magistratur gelangte, weil er aus dem Kreis der Freunde des Augustus ausgeschlossen worden war. Diese Feindschaft war trotz seiner Rückkehr nach Rom von Tiberius aufrechterhalten worden. ${ }^{17}$ Diese Geschichte zeigt, dass die Gunst des Prinzeps, auch wenn sie unter Augustus die formelle Versammlung der Komitien zur Wahl nicht ersetzte, diese doch überlagerte und zur unverzichtbaren Bedingung für den Zugang zu einer Magistratur wurde. Und schließlich wird man sich noch an die Formel des Tacitus erinnern, nach der ein bedeutender Senator wie C. Poppaeus Sabinus »durch die Freundschaft der Principes das Konsulat und die triumphalen Insignien erlangt hatte« (Augustus für das Konsulat und Tiberius für die triumphalen Insignien). ${ }^{18}$ Die allgemeine Entwicklung wird von Modestin beschrieben, 
einem Juristen des 3. Jahrhunderts und Schüler des Ulpian, als er im Zusammenhang mit der lex des Augustus zum ambitus feststellt, dass »dieses Gesetz in unseren Tagen in Rom in Vergessenheit geraten ist, weil die Wahl der Beamten in der Verantwortlichkeit des Prinzeps steht und nicht von der Gunst des Volkes abhängt «. ${ }^{19}$ Was der Jurist die cura principis nennt, geht auf die Zeit des Anfangs der Kaiserherrschaft zurück und gewinnt mindestens während des gesamten Prinzipats des Augustus Gestalt bei gleichzeitiger Fortdauer der Komitien zu den Wahlen in einer Form, die es noch zu bestimmen gilt. Am Vorhandensein einer augusteischen Gesetzgebung zur Kandidatur bei einer Wahl wird sichtbar, dass der Wahlkampf unter Augustus weiterhin bestand. Man weiß, dass die Wahlen gleich zu Beginn des Prinzipats des Tiberius dem Senat übertragen wurden, aber diese Übertragung bedeutet nicht, dass die kaiserliche Gewalt direkt in die Auswahl der Kandidaten eingriff. Eine Passage der Annalen des Tacitus gibt im Zusammenhang mit den Praetoren den Hinweis, dass im Jahre 60 n. Chr. der Kaiser es ist Nero - in Verbindung mit einer »heißumkämpften Bewerbung« eine Regelung fand und sich so ausnahmsweise in einen Wahlvorgang einmischte, für den der römische Geschichtsschreiber feststellt, dass sie "gewöhnlich dem Urteil des Senats überlassen war.$^{20}$

9 Von einem institutionellen Gesichtspunkt aus war Augustus niemals in der Lage, der Volksversammlung auf autoritäre Weise die Mitglieder der Aristokratie aufzudrängen, die er gewählt sehen wollte. Ausgenommen sind vielleicht Vorgänge im Zusammenhang mit schweren Unruhen in Rom, wie das im Jahre $7 \mathrm{n}$. Chr. der Fall war. ${ }^{21}$ Dagegen verfügte er über Kompetenzen, die es ihm erlaubten, Kandidaten auszuschließen, die er für ungeeignet hielt. So hatte er formal das Recht, die Erklärungen einer Kandidatur eines Mitglieds der Aristokratie zurückzuweisen, solange er in seiner Eigenschaft als Konsul die Zenturiatkomitien für die Wahlen leitete. Aber er machte von diesem Vorrecht nur selten Gebrauch, zum einen, weil er nur von 31 bis $23 \mathrm{v}$. Chr. Konsul war (das Konsulat des Jahres 5 v. Chr. trat er nicht an und das des Jahres $2 \mathrm{v}$. Chr. legte er früh im Jahr nieder, noch bevor die Wahlen für das folgende Jahr stattfanden), und zum anderen überließ er in diesem Zeitraum gezwungenermaßen den Vorsitz in den Komitien häufig seinem Kollegen im Konsulat aufgrund seiner häufigen Abwesenheit von Rom zwischen 27 und 23. Nach 23 v. Chr. konnte er auf die vergleichbaren Interventionen der Konsuln zählen, die der kaiserlichen Macht nahestanden. Das ist es, was im Jahre $19 \mathrm{v}$.Chr. geschah, als C. Sentius Saturninus - der der einzige war, der im Jahre 20 für das Konsulat des Jahres 19 in das Konsulat gewählt worden war, und in dieser Stellung seinen Kollegen wählen lassen musste - sich weigerte, die Kandidatur des L. Egnatius Rufus für gültig zu erklären. Das führte zu einer Verschwörung und zur Hinrichtung des Letzteren (s. o.). Davon abgesehen konnte Augustus auch Einfluss auf die Liste der Kandidaten nehmen, indem er sie unterstützte und durchblicken ließ, dass er seine Stimme dem einen oder anderen gab. Er nutzte so sein Recht auf eine commendatio oder suffragatio und traf auf diese Weise eine Auswahl, die de iure nicht zwingend war, aber von der man sich doch vorstellen kann, dass ihr de facto Rechnung getragen wurde. ${ }^{22}$ Im Übrigen waren nicht alle Rechte des Augustus in diesem Bereich formell festgelegt, sie konnten auch in den privaten Bereich gehören. Das beste Beispiel dafür ist das eines Kandidaten für das Konsulat, dem Augustus angeblich geraten hatte, sich nicht zu bewerben. Es handelt sich dabei um eine wirksame Art des Eingreifens, die dem Prinzeps einen negativen Einfluss verschaffte und die aufgrund ihres informellen Charakters in den Quellen nicht sehr häufig belegt ist. Man wird daher im wesentlichen Tacitus folgen, wenn er in 
Hinblick auf die Wahlen unter Augustus klarstellt, dass die wichtigsten dem arbitrium des Prinzeps unterworfen waren: potissima arbitrio principis. ${ }^{23}$

Das Konsulat war unter dem Prinzipat des Augustus nicht die einzige begehrte Ehrenstellung und auch nicht, wie vorher, die höchste in einer neu aufgestellten Hierarchie. In dieser Hinsicht lässt sich ein deutlicher Wandel feststellen: die gewesenen Praetoren trachten nicht mehr nach dem Konsulat, um die mit diesem Amt verbundenen Machtmittel $\mathrm{zu}$ gewinnen; diese waren mit der Etablierung der kaiserlichen Gewalten ihres Inhalts beraubt worden. Es ging ihnen jetzt um den konsularischen Rang, der ihnen den Zugang zu den begehrtesten Posten in der Verwaltung der Provinzen eröffnete. ${ }^{24}$ Unter diesen waren für die ehemaligen Konsuln am Ende die Prokonsulate von Africa und Asia die angesehensten geworden. Davon wird im Zusammenhang mit dem System der Auswahl der Provinzstatthalter noch die Rede sein.

11 Die Wahlen waren in der Zeit der Republik nicht das einzige Mittel, um zwischen den Aristokraten, die nach honores trachteten, eine Entscheidung zu treffen. $\mathrm{Zu}$ rechnen war auch mit der Bestimmung durch das Los, der sortitio, als einer weiteren Art und Weise, in der Konkurrenz zwischen Aristokraten zu vermitteln. Es war in diesem Fall das Los, das unter den Kandidaten für die Prokonsulate vom Rang eines Praetors oder Konsuls entschied, und das wurde umso mehr akzeptiert, als es die Entscheidung der Götter widerzuspiegeln schien. Es ist wohlbekannt, dass Augustus nach dem Erlass einer lex Iulia über die senatorischen Provinzen im Jahre $27 \mathrm{v}$. Chr. die Bestimmung durch das Los wiederherstellte. ${ }^{25}$ Diese Maßnahme wird in der Regel und zu Recht als ein Element des Programms zur Wiederherstellung der res publica angesehen. ${ }^{26}$ Dieser Rückgriff auf eine republikanische Praxis nach der Unterbrechung während des Triumvirats bot für Augustus den Vorteil, sich nicht in die internen Kämpfe innerhalb der Aristokratie einmischen zu müssen. In Wahrheit waren die Senatoren, die sich bewarben, nicht sehr zahlreich, denn das System, wie es im Jahre $27 \mathrm{v}$. Chr. eingeführt worden war, achtete darauf, die Kandidaten vorher so auszufiltern, dass eine möglichst geringe Zahl enttäuscht wurde. ${ }^{27}$ Die allgemeine Entwicklung ging in die Richtung einer Verstärkung der Konkurrenz aufgrund der Erhöhung der Zahl der Praetoren und Suffektkonsuln.

Für die von einem Praetor verwalteten senatorischen Provinzen genügte die Anzahl der jedes Jahr gewählten Praetoren - das waren acht im Jahre 27, und die Zahl stieg in den darauffolgenden Jahren vielleicht auf zehn $a^{28}$ - in den ersten Jahren des neuen Regimes nicht, um einen jährlichen Wechsel der sieben oder acht Prokonsuln zu garantieren. ${ }^{29}$ Aus diesem Grunde musste man Lösungen finden, wie die Verlängerung der Funktion und die Entsendung von Beamten, die noch nicht Praetoren gewesen waren (z. B. Aedile oder Quaestoren, die pro praetore handelten), oder von privati, denen $\mathrm{zu}$ diesem Zweck ein imperium übertragen wurde. Die allmähliche Erhöhung der Zahl der Praetoren - zwölf unter Tiberius - trug dazu bei, die Konkurrenz zwischen den ehemaligen Inhabern dieses Amtes zu erhöhen. Man hat im Übrigen allen Anlass für die Auffassung, dass im Rahmen einer Verwaltung des Reichs, die zahlenmäßig weiterhin wenig entwickelt war, die sieben oder acht jährlichen Prokonsulate praetorischen Rangs unter Augustus honores waren, die unter den Angehörigen der Senatsaristokratie besonders begehrt waren. ${ }^{30}$

Die 28 v. Chr. erfolgte Unterbrechung der Praxis Caesars und der Triumvirn, neben den ordentlichen Konsuln jedes Jahr mehrere Suffektkonsuln zu bestimmen, hatte für die 
senatorischen Provinzen konsularischen Rangs zur Folge, dass sich die Zahl der Männer konsularischen Rangs verringerte, die normalerweise fünf Jahre nach ihrem Konsulat bei der Verlosung der Prokonsulate von Africa und Asia kandidieren konnten. Für die Übertragung dieser beiden Provinzen zwischen Konsularen bestand also in der Tat Konkurrenz, da es mehr Kandidaten gab, als Posten zu vergeben waren, aber sie war reguliert durch Kriterien der Zulassung zur Verlosung, aufgrund deren auf alle Fälle nicht sehr viele Kandidaten übrig blieben. ${ }^{31}$ Im Laufe der $20 \mathrm{er} \mathrm{Jahre} \mathrm{v.} \mathrm{Chr.} \mathrm{wird} \mathrm{die}$ Situation im Zusammenhang mit der Monopolisierung des Konsulats durch Augustus kritisch. Wie bereits hervorgehoben wurde, hatte diese Entscheidung die Verminderung der Männer konsularischen Rangs zur Folge und damit auch der möglichen Kandidaten für die Verlosung der Provinzen Africa und Asia. Ohne Frage kam es aus diesem Grunde dazu, dass die Amtszeit zweier Prokonsuln von Asia Sex. Appuleius und Potitus Valerius Messala - am Ende der 20er Jahre v. Chr. um ein weiteres Jahr verlängert wurde.$^{32} \mathrm{Im}$ Verlauf des ersten Jahrzehnts v. Chr. findet man dann eine relative Stabilisierung der Vergabe der beiden senatorischen Provinzen in konsularischem Rang, und zwar in dem Sinne, dass die beiden jedes Jahr regulär gewählten Konsuln meistens die einzigen Kandidaten suo anno für die Prokonsulate von Africa und Asia waren, d. h. wenn sie unter Einhaltung der von der lex Iulia des Jahres $27 \mathrm{v}$. Chr. bestimmten Regeln an der Reihe waren..$^{33} \mathrm{Um}$ die Zeitenwende ergab sich schließlich, dass sich die Zahl der potentiellen Kandidaten für die konsularischen Prokonsulate erhöhte, nachdem Augustus entschieden hatte, mehr als zwei Konsuln pro Jahr wählen zu lassen, und er so ab $5 \mathrm{v}$. Chr. systematisch auf einen oder zwei Suffektkonsuln zurückzugriff.

Man beobachtet also am Ende für die Prokonsulate konsularischen Rangs dieselbe Entwicklung wie für die praetorischen Rangs: Die schrittweise Erhöhung der Zahl der Praetoren und der Suffektkonsuln trug dazu bei, die Konkurrenz bei der Verlosung der senatorischen Provinzen zu beleben. Das lässt darauf schließen, dass eine derartige Entwicklung sich mit der Festigung des neuen Regimes keineswegs abschwächte, sondern sich in den letzten beiden Jahrzehnten des Prinzipats des Augustus verstärkte. Man sieht, wie sehr Konkurrenz (zwischen Aristokraten mit Ausnahme des Prinzeps) und Konsens (über die monarchische Natur des Regimes) Hand in Hand gingen.

Augustus fand noch ein weiteres Mittel, auf die aristokratische Konkurrenz Einfluss zu nehmen und sie zu regulieren. Er selbst erhöhte die durch den Bürgerkrieg reduzierte Zahl der patrizischen Familien im Laufe seines fünften Konsulats, d. h. im Jahre 29 v. Chr., und zwar auf Anordnung des Volks und des Senats, kraft einer lex Saenia, die von einem Suffektkonsul, einem L. Saenius, am Ende des Jahres $30 \mathrm{v}$. Chr. eingebracht worden war. ${ }^{34}$ Die von Augustus selbst getätigte Auswahl hatte direkten Einfluss auf den sozialen Status und die politische Karriere der Aristokraten, da der Zugang zum Patriziat die Tür zu besonderen Funktionen öffnete. Dazu zählten vor allem die Priesterämter, die dieser Elite der Elite vorbehalten waren, und zudem erlaubte das Patriziat die Vergünstigung eines beschleunigten cursus honorum (Überspringen des Volkstribunats, der Aedilität und der Funktionen eines Praetors mit der Möglichkeit, durchschnittlich im Alter von 32 Jahren zum Konsulat aufzusteigen, während das Durchschnittsalter bei den Plebeiern bei 40 Jahren lag). ${ }^{35}$ 


\section{Politische Rituale und Konkurrenz unter Augustus}

16 Der natürliche Wettbewerb, der in der augusteischen Zeit die Mitglieder der Aristokratie weiterhin zu Rivalen machte, erstreckte sich nicht nur auf den Kampf um die Magistraturen und die Statthalterschaften der Provinzen sowie die Erlangung des Statuts eines Patriziers und der damit verbundenen Vorteile. Hier sind ebenfalls die politischen Rituale hinzuzurechnen, die den römischen Aristokraten oder seine Familie hervortreten ließen und deren Ursprung in der republikanischen Zeit lag. Unter den wichtigsten sind da die verschiedenen Umzüge, die der dadurch geehrten Persönlichkeit oder ihrer Familie ein sichtbares öffentliches Ansehen verliehen. Der Sieg des Augustus bei Actium und die Einrichtung eines neuen Regimes machten aus dem Princeps einen Würdenträger, dessen öffentliche Auftritte die der anderen Senatoren übertrafen, ohne dass Letztere indes völlig verschwanden.

- Die profectio. Der Aufbruch der Statthalter in ihre Provinzen war unter Augustus weiterhin eine öffentliche Zeremonie, die nach Lage der Dinge mehrmals pro Jahr veranstaltet wurde und stets durch große Feierlichkeit gekennzeichnet war. Das zeigt Livius, wenn er feststellt, dass das Schauspiel, das darin bestand, die urbs mit einem paludamentum bekleidet $\mathrm{zu}$ verlassen, immer (d.h. zu seiner Zeit) mit großer dignitas und großer maiestas begangen wurde. ${ }^{36}$ Wie für die republikanische Zeit ${ }^{37}$ muss man an Einzelheiten denken wie die frequentia der Menge, die dem Aufbruch des Statthalters beiwohnte. Dabei waren die Zahl der anwesenden Personen und ihr sozialer Status feste Kriterien, die zählten, um den Grad des Erfolgs des Zugs zu bewerten und die Bedeutung der Persönlichkeit $\mathrm{zu}$ messen, die sich anschickte, das pomerium zu überschreiten. Aber die nunmehr ständige Existenz eines princeps an der Spitze der res publica fügte eine Variante hinzu, die keineswegs unbedeutend war und nicht ohne Folgen für die Wirkung, den Ablauf und den eingeschlagenen Weg des Umzugs. Zunächst muss man erwähnen, dass die Abreisen des Augustus aus Rom, die in der ersten Hälfte des Prinzipats häufig waren - mindestens sechs Mal in den Jahren 27, 22, 16, 12, 11 und 8 v. Chr. -, jede andere profectio eines anderen Senators auf dem Weg in seine Provinz an dignitas und maiestas übertrafen. Dem ist noch hinzuzufügen, dass eine eventuelle Anwesenheit des Augustus, wenn er in Rom war und an dem Geleit des Statthalters bis an die Tore der urbs teilnahm, dazu beitrug, das Ansehen der Zeremonie zu erhöhen. Er konnte bei dieser Gelegenheit die Überlegenheit seiner Stellung bestätigen, indem er dem Statthalter bei seiner Abreise eigens Anweisungen überreichte. Das war eine Praxis, die ohne Frage mit Augustus ihren Anfang nahm - mit Sicherheit gegenüber seinen eigenen Legaten -, um dann zu einem unbestimmten Datum allgemein bei allen Arten der Statthalter eingeführt zu werden. ${ }^{38}$ Der Vorrang der kaiserlichen Macht zeigte sich am Ende dauerhaft von dem Augenblick an, als nach der Errichtung des Forums des Augustus beschlossen wurde, dass dieser monumentale Komplex der neue Ausgangspunkt des Wegs durch die Stadt sein solle, den jeder römische Würdenträger beim Verlassen der urbs einschlug. ${ }^{39}$ Das ist ein Anzeichen dafür, dass das zuvor betonte Phänomen einer Schlichtung der Rivalitäten zwischen Aristokraten durch den Prinzeps ein politisches Phänomen ist, dessen Wirkung in den Augen der Zeitgenossen des Augustus visueller Art sein konnte.

18 - Der Triumph und die Triumphinsignien. Es steht fest, dass vom Jahre $19 \mathrm{v}$. Chr. an die Triumphfeiern von Augustus und den Mitgliedern der kaiserlichen Familie monopolisiert wurden. Das bedeutet aber nicht, dass die Aristokraten kein Interesse 
mehr an den militärischen Auszeichnungen hatten, die siegreichen Feldherrn zuerkannt wurden. Man muss zuallererst klarstellen, dass neben Augustus, dessen dreifacher Triumph im August $29 \mathrm{v}$. Chr. lange Zeit in Erinnerung blieb, acht (andere) Prokonsuln dafür bekannt sind, zwischen Actium und dem Jahr 19 einen Triumph gefeiert zu haben. ${ }^{40}$ Das zeigt, dass in der betreffenden Periode diese höchste militärische Auszeichnung eine Ehre war, die weiterhin in der Reichweite anderer Aristokraten als dem Prinzeps lag und hinreichend selten blieb, um dem Triumphator eine hierarchische Überlegenheit an der Spitze einer Aristokratie zu sichern, die sich damals in einer Phase der Umgestaltung befand. Aber von Actium an und bis zur Rückgabe der Provinzen an den Senat und das römische Volk am 13. Januar 27 bewahrte der Prinzeps die Stellung eines Oberbefehlshabers des Reichs, und das erklärt ohne Zweifel, warum er die nach 31 in Gallien von einem anderen Prokonsul, nämlich von C. Carrinas errungenen Siege in den Triumph von 29 eingliederte. ${ }^{41}$ Von 27 bis 19 griff er nicht direkt in die Feier der Triumphe ein, zumindest nicht in die, die sich aus Siegen nach 27 ergaben, und jene, die 21 dem L. Sempronius Atratinus und 19 dem L. Cornelius Balbus zugesprochen wurden, aber er hielt sich auch nicht aus den Verfahren heraus, die zu der Auszeichnung des einen oder anderen siegreichen Generals führten. Die sehr wahrscheinliche Vermutung ist, dass der Triumph keinesfalls vom Senat ohne Zustimmung des Prinzeps gewährt werden konnte, gleich ob die Siege nun vor oder nach der Rückgabe der Provinzen an den Senat und das römische Volk im Januar 27 und den sich daraus ergebenden Reformen errungen worden waren. Diese These verstärkt die Vorstellung von einer Beherrschung dieser Zeremonie durch die kaiserliche Macht.

Die Monopolisierung des Triumphs durch Augustus und seine domus vom Jahr 19 an bedeutet nicht, dass es keine Kriterien der Auszeichnung mehr gab, die eine der wesentlichen Qualitäten hervorhob, die der römischen Aristokratie eigen waren, die virtus. Das neue Regime schuf zu diesem Zweck eine neue Art militärischer Ehren in Form der Triumphalinsignien, die im Laufe des Jahres $10 \mathrm{v}$. Chr. zum ersten Mal verliehen wurden..$^{42}$ Das war eine Auszeichnung, die unter hierarchischen Gesichtspunkten unterhalb des Triumphs und der Ovation lag, aber für die Mitglieder der augusteischen Aristokratie, die nicht zur kaiserlichen Familie gehörten, zur höchsten militärischen Ehre und zugleich zum Zeichen der kaiserlichen Gunst wurde. Die Bestimmung des Kultgesetzes des Tempels des Mars Ultor, die vorschrieb, innerhalb der Grenzen des Forums des Augustus Bronzestatuen der Generäle zu errichten, denen die Triumphalinsignien zuerkannt worden waren, war in dieser Hinsicht eine bezeichnende Maßnahme. Sie zeigt, in welchem Maße die Erscheinung der Konkurrenz innerhalb der Aristokratie weiterbestand und sich an die neue Situation anpasste. ${ }^{43}$ Die so zur Schau gestellten Aristokraten, ausnahmslos Konsulare, kamen in den Genuss einer seltenen Ehre, die es ihnen ermöglichte, andere Konsulare in der sozialen Hierarchie zu übertreffen. Zugleich erinnerte der Ort der Aufstellung dieser Statuen selbst an das Gewicht, das der in diesem Bereich ausgeübten Protektion des Augustus zukam, der doch kaum unbeteiligt an der Entscheidung war, diesem oder jenem Feldherrn derartige Insignien zu verleihen. ${ }^{44}$

20 - Pompa funebris. Die anlässlich des Todes des Augustus im August und September $14 \mathrm{n}$. Chr. veranstalteten Feiern waren grandios und vor allem von der Aufrechterhaltung des von alters her überlieferten Brauchtums gekennzeichnet, das darin bestand, die wächsernen Gesichtsmasken (imagines) der Vorfahren im Trauerzug mitzuführen und einen oder mehrere Grabreden zu halten. Man weiß etwa, dass bei 
dieser Gelegenheit Porträts der großen Persönlichkeiten der römischen Geschichte zur Schau gestellt wurden wie das des Pompeius, der stricto sensu kein Angehöriger der kaiserlichen Familie war. Dahinter stand ohne Zweifel das offensichtliche Bemühen des neuen Regimes, sich in eine historische Kontinuität einzuschreiben ${ }^{45}$ In Übereinstimmung mit dem, was in Hinblick auf die profectio und den Triumph hervorgehoben wurde, wurde diese Bestattungspraxis zwar von der kaiserlichen Macht eingesetzt, um ihre Legitimität zu stärken, wurde aber von dem neuen Regime nicht als politisches Ritual monopolisiert. Harriet Flower hat dagegen unterstrichen, dass diese Veranstaltungen weiterhin »machtvolle Symbole des Rangs und des politischen Anspruchs waren, sowohl innerhalb wie auch außerhalb des aristokratischen Hauses «. ${ }^{46}$ Aus den Begräbnisfeierlichkeiten und den bei dieser Gelegenheit vorgetragenen Grabreden schöpft Tacitus seine Informationen, wenn er bei zahlreichen Gelegenheiten den Tod von Senatoren unter dem Prinzipat des Tiberius erwähnt, die in der augusteischen Zeit Konsuln gewesen waren, und er zählt die wichtigsten Ehren auf, die ihnen verliehen wurden ${ }^{47}$ Die Lektüre der Beschreibungen dieser Begräbnisfeiern lässt ermessen, welches die wesentlichen Auszeichnungen waren, die dazu dienten, die neue interne Hierarchie der augusteischen Aristokratie festzulegen: nämlich der konsularische Rang, die Funktionen, die sich aus ihm ergaben (das Prokonsulat von Africa oder Asia und die Praefektur der Stadt), sowie die Verleihung der Triumphalinsignien. ${ }^{48}$ Ein anderes grundlegendes Dokument zu diesem Thema ist das Senatus consultum de Cn. Pisone patre. Es handelt sich um eine 1996 veröffentlichte Inschrift, die den Text eines Senatsbeschlusses wiedergibt, der Piso im Jahre $20 \mathrm{n}$. Chr. nach dem Tod des Germanicus verurteilte. Es geht daraus hervor, dass es in Zukunft verboten sei, in einer pompa funebris zum Gedenken des Todes eines Mitglieds der gens Calpurnia die imago Pisos mitzuführen. ${ }^{49}$ Man muss e contrario daraus schließen, dass der traditionelle Brauch, bei Bestattungen die Porträts der Vorfahren mitzuführen, die Magistraturen bekleidet hatten und deren Andenken nicht der Ächtung anheimgefallen war, von den adligen Familien der augusteischen Zeit aufrechterhalten wurde, die die Bürgerkriege überlebt hatten und sich auf eine republikanische Tradition und Geschichte stützen konnten..$^{50}$

\section{Auf der Suche nach dem fauor principis: Die aula Caesaris als weiterer Bereich der aristokratischen Konkurrenz}

21 Die Konkurrenz unter den Aristokraten fand ihren topographischen Rahmen vorrangig an den öffentlichen Orten wie denen der Senatssitzungen oder der Versammlungen der Komitien und denen der vielfältigen offiziellen Zeremonien, die wir gerade beschrieben haben. Eine der Besonderheiten der augusteischen Zeit (und der Kaiserzeit) ist es, dass all diesen Orten ein weiterer Raum der Macht und des Einflusses hinzugefügt und übergeordnet wurde, nämlich der Hof, den man auf lateinisch aula Caesaris nennt. Die Schaffung des Prinzipats durch Augustus führte zu der allmählichen Etablierung einer solchen Struktur, die untrennbar mit jeder monarchischen Gewalt verbunden ist, aber in Rom besondere Formen annahm. ${ }^{51}$ Der Hof kann als der erweiterte Hausstand des Monarchen definiert werden, der das Gefolge des Herrschers im weitesten Sinne umfasste und zugleich politische Funktionen erfüllte. Zu Letzteren zählte auch die Schlichtung im Bereich der aristokratischen Konkurrenz. Das erscheint umso 
selbstverständlicher, als die Nähe zum Prinzeps eine der unerlässlichen Voraussetzungen für das Funktionieren der aula Caesaris war und Augustus unter diesen Umständen dazu veranlasst sein konnte, einem bestimmten Senator seine Gunst $\mathrm{zu}$ zeigen oder sie ihm $\mathrm{zu}$ entziehen. Aloys Winterling hat gezeigt, dass die Zugehörigkeit zum Hof in Rom in der Hierarchie des Status niemals die Ausübung der Magistraturen des cursus honorum ersetzt hat und der Status des "Höflings « für einen Senator in Hinblick auf das soziale Prestige keinerlei Bedeutung hatte. Diese unbestreitbare Tatsache ist der Ursprung von Spannungen, welche sich auf die möglichen Diskrepanzen gründeten, die es zwischen der hohen sozialen Stellung eines Konsulars geben konnte und seinem geringen Ansehen, das er beim Prinzeps genoss, oder umgekehrt zwischen dem niedrigen Status eines Freigelassenen und der kaiserlichen Gunst, die er genoss. Der Hof - oder das, was wir für die ersten Jahrzehnte des Prinzipats die Vorform eines Hofes nennen könnten - war in jedem Falle ein zugleich öffentlicher wie privater Raum, in dem Augustus sich in der Lage befand einzugreifen, um einen bestimmten Aristokraten zu begünstigen oder im Gegenteil abzuwerten. So ist das Privileg, früh am Morgen von Augustus in seinen Gemächern empfangen zu werden, oder bei der morgendlichen salutatio besondere Beachtung zu genießen oder zum abendlichen Bankett auf dem Palatin eingeladen zu werden, stets ein Zeichen besonderer Wertschätzung, die der betreffende Aristokrat nicht versäumen durfte zur Geltung zu bringen, um seine Position zu sichern. Solche Zeichen der Gunst hatten zwar keinerlei Folgen in Hinblick auf den sozialen Status, aber spiegelten sowohl die Tatsache, dass weiterhin ein aktiver politischer Kampf herrschte, als auch den Grad des Einflusses auf den Mann wider, der in Rom den ersten Platz einnahm. Das weiter oben beschriebene Missgeschick des D. Silanus ist ein Hinweis auf die negativen Folgen für die Karriere eines Senators, dem der Prinzeps seine Freundschaft entzog. Auch wenn es in Rom keine "höfische Gesellschaft« gab, gab es doch die Praktiken eines Hofes, und sie schufen Rituale, die für das Kräfteverhältnis innerhalb der augusteischen Aristokratie sehr aufschlussreich sind. Sie bestanden neben den alten Strukturen der Stadt und machten so die Konkurrenz zwischen Aristokraten in der augusteischen Zeit zu einer Erscheinung, die sich erhielt und zugleich eine eigene Form annahm.

\section{Die domus der Aristokraten als Kriterium der Differenzierung}

Der Wohnort der Aristokraten war in Rom niemals ein neutraler oder völlig privater Raum, sondern er hatte eine politische und soziale Bedeutung..$^{52}$ Ohne so weit zu gehen, einen standardisierten Typ von domus als einer bestimmten sozialen Kategorie zugehörig zu identifizieren, haben neuere Untersuchungen doch die politische Dimension eines Ortes unterstrichen, der es seinem Besitzer erlaubte, seine Sichtbarkeit auf der öffentlichen Szene zu verstärken. ${ }^{53}$ Der aristokratische Charakter der römischen Gesellschaft in der spätrepublikanischen Zeit veranlasste die herausragenden gentes und ihre wichtigsten Mitglieder zu einem Wettbewerb, der aus dem Haus eines der Kriterien der Differenzierung machte und infolgedessen zu einem Ort der Macht. Dieser Befund gilt mutatis mutandis auch für die augusteische Epoche. Der hauptsächliche, aber doch beträchtliche Unterschied liegt in der Entwicklung, die zur Ausdehnung des Hauses des Augustus auf dem Palatin führt und dem Prinzeps erlaubt, alle anderen Aristokraten in diesem Bereich zu übertreffen. Dieser Vorgang 
vollzog sich indes allmählich und berechtigt nicht dazu, in der Wohnstätte des Augustus eine palastähnliche Struktur zu sehen. ${ }^{54}$ Und im Übrigen bedeutet sie nicht das Ende der fortwährenden Suche der Aristokraten nach Gleichwertigkeit zwischen ihrer domus und ihrer Stellung an der Spitze der römischen Gesellschaft. Insbesondere die genaue Lage ihres Wohnorts in Rom war ein Faktor, der in der augusteischen Zeit weiterhin in Rechnung gestellt wurde und stets Gegenstand eines Wettbewerbs unter Aristokraten blieb. Für die großen Familien der republikanischen Zeit war es traditioneller Brauch, in der Nähe des Forum Romanum zu wohnen und vor allem auf den verschiedenen Anhöhen, die sich am Rande dieses Ortes erhoben, der doch das Herz des politischen Lebens war. Diese Vorliebe blieb unter den angesehensten gentes der Reichsaristokratie unter Augustus und seinen ersten Nachfolgern erhalten, wie die bei Tacitus in Verbindung mit den Häusern der Senatoren mehrmals verwendete Formel domus foro imminens anzeigt. ${ }^{55}$ Die Zeugnisse über den Prozess Pisos im Jahre 20 v. Chr. erwähnen, dass das Haus dieses Aristokraten zum Zeitpunkt seiner Rückkehr nach Rom auch Schauplatz öffentlicher Veranstaltungen war. Diese Feste und Bankette stärkten die Aufmerksamkeit für die gens Calpurnia, wurden aber von Tacitus getadelt, weil sie in der Atmosphäre der Trauer stattfanden, die sich nach dem Tod des Germanicus verbreitete. ${ }^{56}$ Das Senatus consultum de Cn. Pisone patre hebt die politische Funktion dieser domus hervor und fährt dann fort, dass von den Kuratoren der öffentlichen Orte mit gerichtlicher Vollmacht beseitigt und zerstört werden solle, "was Cn. Piso der Vater oberhalb der Porta Fortunalis erbaut hatte, um private Wohnstätten zusammenzufassen.$^{57}$ Erst mit dem Brand Roms im Jahre 64 und durch die darauffolgenden Errichtung der domus aurea durch Nero wurden die Aristokraten gezwungen, das Zentrum von Rom zu verlassen und die umliegenden Hügel $\mathrm{zu}$ bewohnen (Quirinal, Viminal, Caelius, Aventin), und so fand diese Art von Konkurrenz ihr Ende. ${ }^{58}$

\section{Zusammenfassung: (Neu)gestaltung(en) der Konkurrenz unter den Aristokraten in der Zeit des Augustus}

23 Nach seinen Siegen über Mark Anton und Kleopatra von 30/31 v. Chr. begriff Octavian/ Augustus sehr schnell, dass er demnächst neue Felder der Konkurrenz für die Senatoren finden musste, die sich sehr wohl bewusst waren, dass die reale Macht ihnen nach und nach entglitt, während sich das neue Regime festigte. Daraus erklärt sich, dass die Konkurrenz unter Aristokraten als charakteristischer Zug der römischen "politischen Kultur" in der augusteischen Zeit nicht verschwand, sondern sich veränderte, um sich an das neu etablierte Regime anzupassen. Außer in Fällen von Usurpation war die Konkurrenz sehr schnell, auf jeden Fall seit den Jahren vor 10 v. Chr., kein Kampf mehr um die höchste Gewalt, die nun dem Prinzeps und seiner domus vorbehalten war. Sie blieb aber doch nicht weniger präsent in einer augusteischen Gesellschaft, die sehr stark hierarchisiert blieb, selbst wenn die hierarchischen Kriterien sich in der Zeit zwischen dem Ende des republikanischen Staats nach Actium und dem Tod des Augustus veränderten. Seit den Arbeiten von Ronald Syme weiß man sehr wohl, dass die Schaffung des Prinzipats vom sozialen Standpunkt her als eine aristokratische Restauration betrachtet werden kann, die sich als eine »Rearistokratisierung« nach der Unterbrechung des Triumvirats bezeichnen 
lässt oder "als eine grandiose neo-aristokratische Stabilisierung", um eine gelungene Charakterisierung von Aldo Schiavone wiederaufzugreifen..$^{59}$ Dieser Vorgang führte zu einer sozialen Neuordnung, die zum Ergebnis hatte, dass die Struktur der römischen Gesellschaft noch stärker hierarchisiert und noch komplexer wurde als unter der Republik. Das erklärt den Umstand, dass die Konkurrenz zwischen Aristokraten im gesamten Verlauf des augusteischen Prinzipats so lebhaft blieb.

Die verschiedenen Rituale des politischen Lebens in Rom, von denen man unter der Republik in erster Linie die profectio, die Rückkehr nach Rom, die eventuelle Feier eines Triumphs und die pompa funebris nennen kann, wurden auch nach der Ergreifung der Macht durch Augustus von der römischen Aristokratie weiterhin gefeiert. Ihr Fortbestand und ihr Ablauf zeigen, dass die Grundlagen einer gehobenen sozialen Stellung immer noch die Wahl in das Konsulat, die Erlangung einer Statthalterschaft in den Provinzen und der militärische Sieg blieben. Hinzuzufügen ist die Erhebung in den Rang eines Patriziers. Die Schaffung der kaiserlichen Machtpositionen und ihre Überlegenheit setzten eine Entwicklung in Gang, die dazu führte, dass der konsularische Rang mehr bedeutete als die eigentliche Ausübung des Konsulats, und die dazu beitrug, aus dem Prokonsulat in Africa und Asia den Höhepunkt der Karriere eines Senators zu machen. Augustus stellte sich über das Volk oder setzte sich gar an seine Stelle, um die Konkurrenz zwischen Aristokraten in ihre Bahnen zu lenken und sie zugleich zu entscheiden. Zunächst kontrollierte er den Zugang zu den hohen Magistraturen, indem er in die gelegentlich unruhigen Wahlkampagnen eingriff und die unerwünschten Kandidaten ausschloss, oder er brachte seine Empfehlungen in einer Art und Weise zur Geltung, die zahlreiche Forschungsdiskussionen ausgelöst hat. Es gelang ihm ebenfalls, die Wahl der Prokonsuln zu beeinflussen, indem er auf informellem Wege und im Vorhinein in die Art der Designation durch das Losverfahren eingriff, dessen Entscheidung so nicht dem Zufall allein zufiel. Und nicht vergessen werden darf, dass er, abgesehen von dem Zugang zu den traditionellen Magistraturen und Promagistraturen, im Rahmen der Vorform eines höfischen Betriebs bestimmten Aristokraten seine Gunst bezeugen konnte, ohne jedoch je die Stellung eines wirklichen Höflings schaffen zu wollen.

Die von Augustus eingenommene Funktion eines Schlichters war keine leichte Aufgabe, denn er musste gleichzeitig mit dem Volk in Verbindung stehen, den Empfindlichkeiten der Aristokraten Rechnung tragen ${ }^{60}$ und notfalls im Falle von Spannungen zwischen dem Volk und der Aristokratie eingreifen. Im konkreten Fall agierte der Princeps pragmatisch, wie das Geschehen der Wahlunruhen von 22-21 und 20-19 v. Chr. zeigt, denen er in beiden Fällen durch Rückgriff auf eine besondere Lösung ein Ende setzte. Seine Rolle als Schlichter scheint sich indes ziemlich schnell gefestigt zu haben, wenn man nach dem Fehlen von Wahlunruhen vom Jahr 19 an urteilt, mit der einzigen Ausnahme der Unruhen des Jahres $7 \mathrm{n}$. Chr. Der von den Aristokraten ausgeübte Druck, das Konsulat oder eines oder mehrere Prokonsulate zu erringen, schwächte sich ständig weiter ab in den Verfahren, die sich zwischen dem Sieg Octavians bei Actium im Jahre $31 \mathrm{v}$. Chr. und seinem Tod $14 \mathrm{n}$. Chr. weiterentwickelten. Die Monopolisierung des einen der beiden Posten eines Konsuls durch Augustus zwischen 31 und 23 und die systematische Unterdrückung des Rückgriffs auf Suffektkonsuln von 28 an schürten zunächst den Wettbewerb zwischen Aristokraten bei der Wahl in die zweite Konsulstelle, die in diesem Zeitraum als einzige zu besetzen war. Auf der anderen Seite hatte das zur nachteiligen Folge, den Kreis der 
Kandidaten für die Prokonsulate von Africa und Asia einzuschränken. Die Niederlegung des Konsulats durch Augustus während des Sommers 23 war eine Entscheidung, die es für einige Zeit erlaubte, dieses besondere Problem zu lösen, und sie wurde im Interesse der Aristokraten getroffen, indem sie ihnen die beiden Posten eines Konsuls überließ. Aber es blieb doch weiter so, dass das Konsulat nur für einen kleinen Teil der Praetoren erreichbar war, die jedes Jahr gewählt wurden und mindestens acht an der Zahl waren. Die Vermehrung der Suffektkonsulate vom Jahre 5 v. Chr. an verminderte den Druck, der auf dem Zugang zum Konsulat lag, indem sie einer größeren Zahl ehemaliger Praetoren erlaubte, Konsul zu werden. Doch verlagerte diese Maßnahme das Problem nur, da die Kandidaten für die einzigen beiden konsularischen Prokonsulate in den letzten zwei Jahrzehnten des Prinzipats des Augustus so immer zahlreicher wurden. Daraus ergibt sich, dass keine der zwischen $31 \mathrm{v}$. Chr. und $14 \mathrm{n}$. Chr. belegten Kombinationen dem Phänomen der aristokratischen Konkurrenz ein Ende setzte, die je nach der angestrebten Funktion und dem jeweiligen Zeitpunkt mehr oder minder lebhaft war. Augustus ließ den Wettbewerb zwischen Aristokraten weiterbestehen, unter der Bedingung, dass er der Schlichter war, denn davon hing die Akzeptanz seines Regimes durch die Aristokratie ab. Er hatte im Übrigen wohl kaum die Wahl. Die Konkurrenz war so weitgehend das Herz und Wesen der römischen "politischen Kultur «, dass sie unter dem Prinzipat des Augustus fortleben konnte und sich an eine zunehmend monarchische Umgebung anpasste.

\section{BIBLIOGRAPHIE}

Bibliographie

Baudry, R. (2008): Les patriciens à la fin de la République et au début du Principat, unveröffentlichte Doktorarbeit an der Universität Paris 1.

Beck, H / Dupla, A. / Jehne, M. / Pina Polo, Fr. (2011): »The Republic and its Highest Office: Some Introductory Remarks on the Roman Consulate«, in: Beck, H. / Dupla, A. / Jehne, M. / Pina Polo, Fr. (Hg.): Consuls and Res Publica. Holding High Office in Republican Rome, Cambridge, S. 1-15.

Birley, A. R. (2000): »Q. Lucretius Vespillo (cos.ord. 19)«, Chiron, 30, S. 711-748.

Bourrit, B. (2006): »Les visages de l'autorité«, L'Homme, 180, S. 97-114.

Bruun, Chr. (1986): „The Career of Sex. Palpellius Hister. The Praetorian Proconsulate during the Early Empire Reconsidered «, Arctos, 20, S. 5-23.

Dalla Rosa, A. (2011): »Dominating the Auspices: Augustus, Augury and the Proconsuls«, in: Richardson, J. H. /Santangelo, F. (Hg.): Priests and State in the Roman World, Stuttgart, S. 243-269.

Dettenhofer, M. H. (2000): Herrschaft und Widerstand im augusteischen Principat. Die Konkurrenz zwischen res publica und domus Augusta, Stuttgart.

Devillers, O. (2003): Tacite et les sources des Annales, Louvain-Paris. 
Eck, W. (1984): »Senatorial Self-Representation: Developments in the Augustan Period«, in: Millar, F. / Segal, E. (Hg.): Caesar Augustus. Seven Aspects, Oxford, S. 129-167 [= deutsche überarbeitete Fassung in Eck, Monument, 2010, S. 1-43].

Eck, W. (1997): „Senatorial domus in Imperial Rome«, SCI, 16, S. 162-190 [= deutsche überarbeitete Fassung in Eck, Monument, 2010, S. 207-239].

Eck, W. (1999a): »Elite und Leitbilder in der Kaiserzeit«, in: Dummer, J. / Vielberg, M. (Hg.): Leitbilder der Spätantike - Eliten und Leitbilder, Stuttgart, S. 31-55 [= Eck, Monument, 2010, S. 251273].

Eck, W. (1999b): »Kaiserliche Imperatorakklamationen und ornamenta triumphalia«, ZPE, 124, S. 223-227 [= Eck, Monument, 2010, S. 241-249].

Eck, W. (2005): »Der Senator und die Öffentlichkeit - oder: wie beeindruckt man das Publikum?«, in: Eck, W. / Heil, M. (Hg.): Senatores populi Romani. Realität und Mediale Präsentation einer Führungsschicht, Stuttgart, S. 1-18 [= Eck, Monument, 2010, S. 333-353].

Eck, W. (2010): »Emperor and Senatorial Aristocracy in Competition for Public Space«, in: Ewald, B. C. / Norena, C. F. (Hg.): The Emperor and Rome. Space, Representation, Ritual, Cambridge, S. 89-110.

Eck, W. (2010): Monument und Inschrift. Gesammelte Aufsätze zur senatorischen Repräsentation in der Kaiserzeit, hg. v. Ameling, W. / Heinrichs, J., Berlin.

Eck, W. / Caballos, A. / Fernández, F. (1996): Das S.C. de Cn. Pisone patre, München.

Eich, P. (2008): »Aristokratie und Monarchie im kaiserzeitlichen Rom«, in: Beck, H. / Scholz, P. / Walter, U. (Hg.): Die Macht der Wenigen. Aristokratische Herrschaftspraxis, Kommunikation und `Edler Lebensstil in Antike und Früher Neuzeit, München, S. 125-151.

Ferriès, M.-Cl. (2007): Les partisans d'Antoine. Des orphelins de César aux complices de Cléopâtre, Bordeaux.

Flower, H. (1996): Ancestor Masks and Aristocratic Power in Roman Culture, Oxford.

Flower, H. (2006): »Der Leichenzug - die Ahnen kommen wieder«, in: Stein-Hölkeskamp, E. / Hölkeskamp, K.-J. (Hg.): Erinnerungsorte der Antike. Die römische Welt, München, S. 321-337.

Frei Stolba, R. (1967): Untersuchungen zu den Wahlen in der römischen Kaiserzeit, Zürich.

Gros, P. (2009): »Les limites d'un compromis historique: de la domus vitruvienne à la maison augustéenne du Palatin«, in: Hurlet, Fr. / Mineo, B. (Hg.): Le principat d'Auguste. Réalités et représentations du pouvoir. Autour de la Res publica restituta, Rennes, S. 169-185.

Hesberg, H von (2005): „Die Häuser der Senatoren in Rom: gesellschaftliche und politische Funktion«, in: Eck, W. / Heil, M. (Hg.): Senatores populi Romani. Realität und Mediale Präsentation einer Führungsschicht, Stuttgart, S. 19-52.

Hinard, Fr. (2003): »Entre République et Principat. Pouvoir et urbanité«, in: Hantos, Th. (Hg.): Laurea internationalis. Festschrift fü Jochen Bleicken zum 75. Geburtstag, Stuttgart, S. 331-358.

Hölkeskamp, K.-J. (2004): Rekonstruktionen einer Republik. Die politische Kultur des antiken Roms und die Forschung der letzten Jahrzehnte, München; fr. Übers.: Reconstruire une République. Antiquité romaine. La »culture politique« de la Rome antique et la recherche des dernieres décennies, übers. von $\mathrm{Cl}$. Layre, hg. v. Fr. Hurlet, Nantes, 2008;

engl. Übers.: Reconstructing the Roman Republic. An Ancient Political Culture and Modern Research, Princeton, 2010 mit wesentlichen Ergänzungen. 
Hölkeskamp, K.-J. (2006): »Konsens und Konkurrenz. Die politische Kultur der römischen Republik in neuer Sicht«, Klio, 88, S. 360-396.

Hölkeskamp, K.-J. (2008): »Hierarchie und Konsens. Pompae in der politischen Kultur der römischen Republik«, in: Arweiler, A. H. / Gauly, B. M. (Hg.): Machtfragen. Zur kulturellen Repräsentation und Konstruktion von Macht in Antike, Mittelalter und Neuzeit, Stuttgart, S. 79-126.

Hollard, V. (2010): Le rituel du vote. Les assemblées romaines du peuple, Paris.

Hurlet, Fr. (2000): »Les sénateurs dans l'entourage d'Auguste et de Tibère. Un complément à plusieurs synthèses récentes sur la cour impériale«, $R P h, 74$, S. 123-150.

Hurlet, Fr. (2001): »Le centre du pouvoir: Rome et la cour impériale aux deux premiers siècles de notre ère«, in: Belayche, N. (Hg.): Rome, les Césars et la Ville aux deux premiers siècles de notrè ère. Études d'histoire politique, sociale et religieuse, Rennes, S. 159-183.

Hurlet, Fr. (2006): Le proconsul et le prince d'Auguste à Dioclétien, Bordeaux.

Hurlet, Fr. (2009): »La Res publica restituta et l'aristocratie augustéenne«, in: Hurlet, Fr. / Mineo, B. (Hg.): Le principat d'Auguste. Réalités et représentations du pouvoir. Autour de la Res publica restituta, Rennes, S. 73-99.

Hurlet, Fr. (2010): »Recherches sur la profectio de la dictature de Sylla à la lex Pompeia (82-52). Le cas des gouverneurs de rang prétorien«, in: Barrandon, N. / Kirbihler, Fr. (Hg.): Administrer les provinces de la République romaine, Rennes, S. 45-72.

Hurlet, Fr. (2011): »Consulship and consuls under Augustus«, in: Beck, H. / Dupla, A. / Jehne, M. / Pina Polo, Fr. (Hg): Consuls and Res Publica. Holding High Office in Republican Rome, Cambridge, S. 319-335.

Hurlet, Fr. (2012): »Démocratie à Rome? Quelle démocratie? En relisant Millar (et Hölkeskamp)«, in: Benoist, St. (Hg.): Rome, a City and Its Empire in Perspective: The Impact of the Roman World through Fergus Millar's Research (Coll. Impact of Empire 16), Leiden.

Lacey, W. (1996): Augustus and the Principate. The Evolution of the System, Leeds.

Laignoux, R. (2010): La construction du pouvoir personnel durant les années 44-29: processus de légitimation, unveröffentlichte Dissertation Paris 1.

Levick, B. M. (1967): »Imperial Control of the Elections under the Early Principate: Commendatio, Suffragatio, and Nominatio, Historia, 16, S. 207-230.

Osgood, J. (2006): Caesar's Legacy: Civil War and the Emergence of the Roman Empire, Cambridge.

Pani, M. (1993): Potere e valori a Roma fra Augusto e Traiano, 2. Aufl., Bari.

Pani, M. (2003): La corte dei Cesari fra Augusto e Nerone, Bari.

Paterson, J. (2007): »Friends in High Places: the Creation of the Court of the Roman Emperor «, in: Spawforth, A. J. S. (Hg.): The Court and Court Society in Ancient Monarchies, Cambridge / New York, S. 121-156.

Phillips, D. A. (1997): »The Conspiracy of Egnatius Rufus and the Election of Suffect Consuls Under Augustus«, Historia, 46, S. 103-112.

Rich, J. W. (1990): Cassius Dio and the Augustan Settlement (Roman History 53-55.9), Warminster.

Robert, R. (2008): »Priuata modo et domestiqua nos délectant. Espace domestique, espace utopique?«, in: Carsana, Ch. / Schettino, M. T. (Hg.): Utopia e utopie nel pensiero storico antico, Rom, S. 111-132. 
Rosillo López, Cr. (2010): La corruption à la fin de la république romaine (IIe-Ier s. av. J.-C.): aspects politiques et financiers, Stuttgart.

Schiavone A. (2003 [1996]): L'histoire brisée. La Rome antique et l'Occident moderne, trad. en français par G. et J. Bouffartigue, Paris.

Swan, P. M. (2004): The Augustan Succession: an Historical Commentary on Cassius Dio's Roman History, Books 55-56 (9 B.C. - A.D. 14), New York.

Syme, R. (1958): »Obituaries in Tacitus«, AJPh, 79, S. 18-31 [= Ten Studies in Tacitus, Oxford, 1970, S. 79-90].

Syme, R. (1952): The Roman Revolution, 2. Aufl., Oxford;

dt Übers.: Die Römische Revolution, übers. v. W. Eichweiler und H. G. Degen, Stuttgart, 2019.

Syme, R. (1986): Augustan Aristocracy, Oxford.

Tansey, P. (2008): »Q. Aemilius Lepidus (Barbula?) cos. 21 B.C.«, Historia, 57, S. 174- 207.

Wallace-Hadrill, A. (1996): »The Imperial Court«, in: Bowman, A. K. / Champlin, E. / Lintott, A. (Hg.): Cambridge Ancient History Bd. X (The Augustan Empire, 43 B.C-A.D. 69), 2. Aufl., Cambridge, S. 283-308.

Winterling, A. (1999): Aula Caesaris. Studien zur Institutionalisierung des römischen Kaiserhofes in der Zeit von Augustus bis Commodus (31 v. Chr.-192 n. Chr.), München.

Winterling, A. (2001): „Cour sans `Etat‘. L'aula Caesaris aux I ${ }^{\text {er }}$ et IIe siècles de notre ère«, in: Belayche, N. (Hg.): Rome, les Césars et la Ville aux deux premiers siècles de notre ère. Études d'histoire politique, sociale et religieuse, Rennes, S. 185-206.

Zaccaria Ruggiu, A. (1995): Spazio privato e spazio pubblico nella città romana, Rom.

\section{NOTES}

1. Hölkeskamp (2004), S. 85-92; vgl. auch Hölkeskamp (2006) und Hölkeskamp (2008).

2. Hölkeskamp (2004), S. 73-84.

3. Laignoux (2010).

4. S. in diesem Sinne die Analyse des Tacitus Ann. 1,2,1, wo festgestellt wird, dass »die Nobiles [...] die sichere Gegenwart der riskanten Vergangenheit vorzogen«; vgl. auch ibid. 1,4,1, wo es um die Frage der Aufrechterhaltung des Friedens durch Augustus geht (Augustus [...] pacem sustentavit).

5. Vgl. das letzte Kapitel in Die römische Revolution von Ronald Syme, das "Pax et Princeps" überschrieben ist, und die ersten Bemerkungen seiner Augustan Aristocracy (Syme [1986], S. 1: "the two orders now expected security and recognition«); vgl. auch die Einleitung der Artikel von Lacey (1996) und Osgood (2006).

6. Dieser Punkt ist bereits ausgiebig von Syme (1952), S. 420 hervorgehoben worden; vgl. auch Syme (1986), S. 1. Man wird dazu Pani (1993), S. 29-37 zitieren, wo mit Recht festgestellt wird, dass die verschiedenen sozialen Kräfte der julisch-claudischen Epoche (d.h. die alte republikanische nobilitas, ein Teil des neuen Senats ...) in der Pax Augusta nicht einfach verschwanden, sondern den politischen Kampf wie zur Zeit der Republik reproduzierten, wenn auch in anderer Form (Volksaufstände, Verschwörungen, Palastrevolten bis zu ihrem "Lebensstil« hin) und ohne etwa die Existenz eines princeps in Frage zu stellen. Vgl. dazu auch Eck (2010b), der die räumliche Dimension eines aristokratischen Wettkampfs beschrieben hat, der in der Kaiserzeit nicht mehr die Stadt Rom zum Austragungsort hatte, sondern die Städte Italiens und der Provinzen. Man findet schließlich auch nützliche Überlegungen zum 
Zusammenspiel zwischen der fortdauernden Konkurrenz unter dem späten Kaisertum und dem Vorhandensein eines princeps an der Spitze Roms und des Reichs bei Eich (2008).

7. Hollard (2010).

8. Für eine zusammenfassende Darstellung des Konsulats während des augusteischen Prinzipats s. Hurlet (2011).

9. Cass. Dio. 53,32,3.

10. Hurlet (2009), S. 95 und Anm. 59 sowie Hurlet (2011), S. 332 und Anm. 38. Vgl. auch die noch immer nützlichen Untersuchungen von Frei Stolba (1967), S. 101-104 und die Darstellung, die Dettenhofer (2000), S. 119 f. gibt.

11. $\mathrm{Zu} \mathrm{Q}$. Aemilius Lepidus (Barbula) und seiner Laufbahn s. die neue und ausführliche

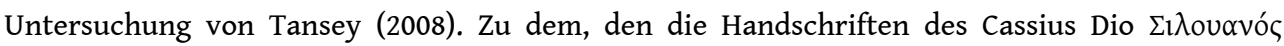
nennen und den man wohl eher als einen L. (Iunius) Silanus identifizieren sollte (es könnte sich

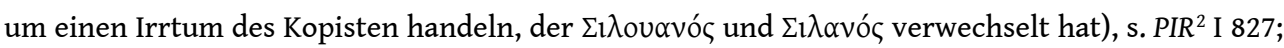
Syme (1986), S. 191; Rich (1990), S. 179; Eck, Der Neue Pauly, Bd. 6, 1999, Sp. 69, und Birley (2000), S. 715, Anm. 17.

12. Cass. Dio 54,6,2-3.

13. Cass. Dio 54,10,1-2; Vell. 2,92. $\mathrm{Zu}$ dieser Episode und $\mathrm{zu}$ Q.Lucretius Vespillo s. die ausführliche Untersuchung von Birley (2000); vgl. auch Dettenhofer (2000), S. 121-124.

14. Vgl. CIL II $2225=$ ILS $8007=$ CIL II 7,397.

15. Den Stand der Forschung bei Frei-Stolba (1967), S. 104-106 (es gibt drei Möglichkeiten, die Wahl dieses Verbs zu erklären: entweder handelt es sich um eine außerordentliche Ernennung durch Augustus ohne eine Befragung der Komitien in einer Notstandssituation, oder um eine verbindliche commendatio, oder um eine unverbindliche commendatio in Verbindung mit einer Liste mit einem einzigen Kandidaten). Man weiß aus dem Zeugnis des Cassius Dio, dass Q. Lucretius Vespillo sich beeilte, nach Rom zurückzukehren, nachdem er von Augustus zum Konsul »ernannt« worden war, und dabei ist die entscheidende Frage, ob eine förmliche Wahl stattgefunden hat oder nicht, um die von Augustus getroffene Entscheidung zu ratifizieren. FreiStolba verneint das und macht geltend, dass der Prinzeps auf eine erprobte Praxis der Triumvirn in einer nicht sehr fernen Vergangenheit zurückgegriffen habe. Aber dieses Argument des Vorbildes überzeugt deshalb nicht, weil Augustus von den Jahren 29-28 an die Exzesse des Triumvirats verurteilt hat und offiziell erklärte, die res publica wiederherzustellen (zu einer förmlichen Beteiligung der Komitien an der Wahl des Q. Lucretius Vespillo vgl. Phillips [1997], S. 111, Anm. 24, und Birley [2000], S. 719 f.).

16. Tac. Ann. 3,75,1.

17. Tac. Ann. 3,24,2-4.

18. Tac. Ann. 6,39,3.

19. Dig. XLVIII 14,1. Zu diesem Text s. Rosillo Lopéz (2010), S. 74.

20. Tac, Ann. 14,28,1 (zu diesem Thema s. Levick [1967], S. 224, Anm. 85).

21. Zu der Ernennung "aller Beamten« durch Augustus im Jahre 7 n. Chr. s. Cass. Dio 55,34,2, der

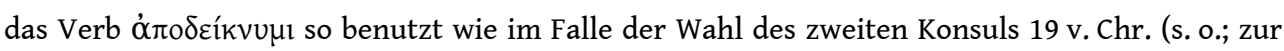
Bedeutung des Verbs s. die verschiedenen Interpretationen, die Frei-Stolba [1967], S.115-116 vorlegt; vgl. auch Swan [2004], S. 220).

22. Zur commendatio und suffragatio sowie $\mathrm{zu}$ dem Unterschied zwischen diesen beiden Vorrechten kann man weiterhin mit Nutzen den Artikel von Levick (1967) heranziehen.

23. Tac. Ann. 1,15,1.

24. Wie Beck / Dupla / Jehne / Pina Paolo (2011), S. 15 hervorgehoben haben.

25. Vgl. Hurlet (2006), S. 24-35.

26. In diesem Sinne Hurlet (2009), S. 82-84.

27. Für eine Beschreibung des Losverfahrens während der ersten Jahre des Prinzipats des Augustus erlaube ich mir, auf meine Untersuchung Hurlet (2006), S. 36-56 zurückzuverweisen. 
28. Vgl. zu diesem Thema Cass. Dio 53,32,2 und Vell. 2,89,3. Cass. Dio 56,25,4 berichtet, im Jahre $11 \mathrm{n}$. Chr. habe es sechzehn Praetoren gegeben, aber er stellt gleichzeitig fest, dass diese beträchtliche Zahl eine Ausnahme geblieben sei und dass die Zahl der Praetoren sich für lange Zeit bei zwölf gehalten habe, d. h. zumindest zu Beginn des Prinzipats des Tiberius (vgl. Tac. Ann. $1,14,4)$.

29. Man muss dabei noch in Rechnung stellen, dass der infolge der lex Iulia von $27 \mathrm{v}$. Chr. auf fünf Jahre festgelegte Abstand zwischen der Praetur und der Führung einer senatorischen Provinz im praetorischen Rang dazu beitrug, die Zahl der Kandidaten für ein praetorisches Prokonsulat bei der Verlosung zu vermindern. Man musste von der Zahl die Praetoren abziehen, die schnell zum Konsulat gelangt waren, und ebenfalls diejenigen, die inzwischen vom Prinzeps an die Spitze einer kaiserlichen Provinz gestellt worden waren oder kurz nach der Praetur verstorben waren. Unter diesen Umständen musste es schwierig sein, jedes Jahr die sieben oder acht notwendigen Kandidaten zur Erneuerung der praetorischen Prokonsulate zu finden, zumindest zu Beginn des Prinzipats des Augustus, als es nicht mehr als acht Praetoren pro Jahr gab.

30. In diesem Sinne Bruun (1986).

31. Der Text bei Cassius Dio 53,14,3 ist in dieser Hinsicht sehr eindeutig, wenn der Autor daran erinnert, dass "zu einer Zeit (was mit Sicherheit auf den Beginn des augusteischen Prinzipats zurückweist) jene, die diese Voraussetzungen erfüllten, auch wenn sie zahlreicher waren als die Provinzen, auf diese Weise erlost wurden«.

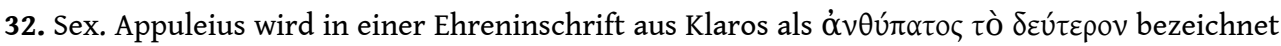
(AE 2000, 1392); was Potitus Valerius Messala betrifft, so präzisiert eine Inschrift aus Rom, dass er [proco(n)s(ul) provinc(iae)?] Asiae bis war (CIL VI 7075 und 41061 = ILS 8964).

33. Man muss dabei noch beachten, dass die Einhaltung der Fünfjahresfrist nicht das einzige in Betracht gezogenen Kriterium war, sondern auch die an das ius liberorum gebundenen Privilegien eine Rolle spielten.

34. Zu der Erhöhung der Zahl der Patrizier im Jahre 29, die vielleicht auf eine erste auf das Jahr 33 zurückgehende Maßnahme in diesem Sinne folgte, wenn man einem Auszug aus Cass. Dio 49,43,6 Glauben schenken will, wird man das eindeutige Zeugnis der Res Gestae Divi Augusti 8,1 heranziehen; vgl. auch Cass. Dio 52,42,5 und kürzer Tac. Ann. 11,25,2. Der Abstand von einem Jahr zwischen dem Jahre 30 (Abstimmung über die lex Saenia) und dem Jahre 29 (Auswahl der neuen Patrizier) erklärt sich aus Gründen der Prozedur. Augustus brachte bei seiner Rückkehr nach Rom im Rahmen seiner lectio senatus das Gesetz zur Anwendung, das ihm einige Monate zuvor die Möglichkeit übertragen hatte, neue Patrizier zu ernennen.

35. Zur Frage des Patriciats in der augusteischen Zeit wird man die Doktorarbeit von R. Baudry heranziehen, die demnächst veröffentlicht werden wird (vgl. vor allem Baudry (2008), S. 362, der $\mathrm{zu}$ Recht feststellt, dass »die Stärkung der Einrichtung des Patriziats doch auch als ein Instrument der Regulierung des aristokratischen Wettbewerbs verstanden werden kann; diese stand unter einer vorangehenden Kontrolle durch den Prinzeps, der entschied, welche die Familien sein sollten, die zur senatorischen Aristokratie zählten«).

36. Liv. 42,49,2; zu den Spezialbegriffen, die das bezeichneten, was man die profectio nennt, s. Hurlet (2010), S. 46, wo daran erinnert wird, dass man in der republikanischen Zeit das Verb exire oder proficisci und das Adjektiv paludatus miteinander in Zusammenhang bringt.

37. Ein gutes Beispiel aus republikanischer Zeit ist das der profectio des Q. Valerius Orca im Jahre 57/56 v. Chr. (Cic. Fam. 13,6,1).

38. S. zu diesem Thema Hurlet (2006), S. 223-232.

39. Suet. Aug. 29,2 und Cass. Dio 55,10,2.

40. Die Liste der Triumphatoren zwischen 31 und $19 \mathrm{v}$. Chr. bietet keinerlei Schwierigkeiten: C. Calvisius Sabinus, Prokonsul der Hispania citerior im Jahre 29/28, dessen Triumph am 26. Mai 28 stattfand; C. Carrinas, Prokonsul der gallischen Provinzen im Jahre 29/28, der seinen Triumph am 14. Juli 28 feierte; L. Autronius Paetus, Prokonsul von Africa im Jahre 29/28, der am 26. August 
28 triumphierte; M. Licinius Crassus, Prokonsul von Makedonien von 30 bis 28, der seinen Triumph am 4. Juli 27 feierte; M. Valerius Messala Corvinus, Prokonsul der gallischen Provinzen im Jahre 28/27 und zurück in Rom als Triumphator am 25. September 27; Sex. Appuleius, Prokonsul der Hispania citerior im Jahre 28/27, der am 26. Januar 26 triumphierte; L. Sempronius Atratinus am 12. Oktober 21; L. Cornelius Balbus am 27. März 19. $\mathrm{Zu}$ diesen Triumphen und den damit verbundenen Monumenten oder Bauten s. Hinard (2003).

41. Cass. Dio 51,21,6, der diese Situation rechtfertigt, indem er erklärt, dass »die Ehre des Sieges rechtlich dem Oberkommandierenden zukam«, d. h. dem Augustus. Dazu vgl. Dalla Rosa (2011), S. 245-253.

42. $\mathrm{Zu}$ den Triumphalinsignien und ihrer Bedeutung in der augusteischen Zeit und vor allem zur Entwicklung der inschriftlichen Praxis des cursus honorum vgl. die von Eck in verschiedenen Aufsätzen veröffentlichten Untersuchungen: Eck (1984), S. 142-145 (= Eck [2010b], S. 25-27); Eck (1999a), S. 42 f. (= Eck [2010b], S. 262 f.); Eck (1999b) (= Eck [2010b], S. 241-249); Eck (2005), S. 8 f. (=Eck [2010b], S. 342 f.); Eck (2010a), S. 93.

43. Cass. Dio $55,10,3$.

44. Die inschriftliche Formel auctore principe senatus ornamenta triumphalia decreuit, die häufig belegt ist (s. eine ausführliche Aufzählung der Belegstellen bei Eck [2010a], S. 93), deutet darauf hin, dass die Entscheidung über die Verleihung der Triumphalinsignien vom Senat getroffen wurde, aber doch »auf Betreiben des Prinzeps«.

45. Zum Begräbnis des Augustus, den unmittelbar vorangehenden Beispielen (vor allem das des Agrippa) und der Verbindung zwischen dem Vorbeitragen der imagines und dem ikonographischen Programm des Augustusforums s. Flower (1996), S. 224-246. Allgemeiner zu den imagines zuletzt Flower (2006) und Bourrit (2006).

46. Flower (1996), S. 256.

47. Der Inhalt der bei dieser Gelegenheit vorgetragenen Trauerreden war für mindestens vier Fälle ehemaliger Konsuln der augusteischen Zeit dem Tacitus umso leichter bekannt, als diese in den Genuss eines öffentlichen Begräbnisses kamen. $\mathrm{Zu}$ den von Tacitus $\mathrm{zu}$ diesem Thema benutzten Quellen s. Syme (1958) und Devillers (2003), S. 55-64. Ebenfalls zu diesem Thema ist eine baldige Veröffentlichung einer Untersuchung von 0 . Devillers $\mathrm{zu}$ erwarten, die er bei Gelegenheit eines von L. Coste und M. Figeac organisierten Kolloquiums zum Thema der Eliten vorgetragen hat (ich danke dem Autor herzlichst, dass er mir den Text seines Artikels noch vor der Publikation zugänglich gemacht hat).

48. Das geht aus der bei Tacitus gegebenen Darstellung der Trauerreden für P. Sulpicius Quirinus, Suffektkonsul im Jahr $12 \mathrm{v}$. Chr. und $21 \mathrm{n}$. Chr. verstorben (Tac. Ann. 3.48,1), und für L. Calpurnius Piso den Pontifex, Konsul im Jahre 15 v. Chr. und verstorben 32 n. Chr. (Tac. Ann. 6,10,3) hervor; vgl. in demselben Sinne auch den von Tacitus präsentierten Nekrolog anlässlich des Todes des L. Volusius, des Suffektkonsuls von 12 v. Chr., im Jahre 20 n. Chr. (Tac. Ann. 3,30,1; man muss noch hinzufügen, dass in diesem Kapitel ebenfalls dem Sallustius Crispus eine Notiz gewidmet ist, einem Ritter, der trotz seines minderen Stands gelobt wird, weil er »an Einfluss viele Triumphatoren und Konsulare« übertroffen habe); außerdem sind da noch Todesfälle aus dem Jahr 25 n. Chr. genannt, und zwar der des Cn. Cornelius Lentulus, des Auguren, regulärer Konsul des Jahres 14 v. Chr., und der des L. Domitius Ahenobarbus, des regulären Konsuls von 16 v. Chr. (Tac. Ann. 4,44,12). Vgl. schließlich noch für die Konsuln der augusteischen Zeit die Notiz, die Tacitus dem Poppaeus Sabinus gewidmet hat, Konsul von 9 n. Chr. und im Jahre $35 \mathrm{n}$. Chr. verstorben (Tac. Ann. 6,39,3).

49. SCDPP I 80-82 = AE 1996, 885 .

50. S. in diesem Sinne Eck / Caballos / Fernandez (1996), S. 196.

51. Die Bibliographie zum kaiserlichen Hof hat sich in den letzten fünfzehn Jahren grundlegend erneuert. S. vor allem Wallace-Hadrill (1996); Winterling (1999); Winterling (2001); Hurlet (2000); Hurlet (2001); Pani (2003); Paterson (2007). 
52. Zu diesem Thema wird man mit Gewinn das Buch von Zaccaria Ruggiu (1995) konsultieren. Vgl. auch Eck (1997) (= Eck [2010b], S. 207-239) und neuerdings Robert (2008).

53. $\mathrm{Zu}$ diesem Thema s. von Hesberg (2005).

54. Dazu s. zuletzt Gros (2009).

55. Tac. Ann. 3,9,3 zu den Calpurnii; Tac. Hist. 3,70,1 zu den Vitellii; vgl. auch in ähnlichem Sinne Tac. Ann. 15,69,1 zu den Iulii Vestini Attici.

56. Tac. Ann. 3,9,3.

57. Vgl. SCDPP I,105-108 = AE 1996, 885 .

58. Vgl. Eck (2010a), S. 102-105.

59. Schiavone (2003), S. 215.

60. Zeugnis dieser Empfindlichkeit der Aristokraten in der augusteischen Zeit ist im Jahre 22 v. Chr. die Weigerung des L. Domitius Ahenobarbus, damals Aedil, dem Zensor L. Munatius Plancus den Vortritt zu lassen (Suet. Ner. 4,2; zu dieser Episode s. die Untersuchung von Ferriès [2007], S. 240, Anm. 32).

\section{INDEX}

Mots-clés : République romaine, concurrence, aristocratie, Auguste, rituel

Schlüsselwörter : römische Republik, Konkurrenz, Aristokratie, Augustus, Ritual

\section{AUTEURS}

\section{FRÉDÉRIC HURLET}

Frédéric Hurlet ist Professor für römische Geschichte an der Universität Paris Nanterre. Nähere Informationen finden Sie hier. 